contemporaneous or later deformation had occurred in the vicinity of the postulated bends. Such deformation might possibly fit into the late Caledonian movements. This problem would be more acute for significant Tertiary (or even post-Devonian) crustal shortening or extension affecting north Britain. The known Tertiary movement is predominantly relatively minor regional extension involved in dyke injection, basin formation and normal faulting.

Collette $^{9,10}$ has presented further evidence to suggest that the line of the Great Glen fault lies east of the Shetland Isles. It is clear that all hypotheses give rise to problems and this should encourage us to look for further evidence particularly in the vicinity of the postulated bends. Perhaps the simplest is the hypothesis advanced by Pitcher"1 that the Walls Boundary fault is a splay of the main fault. The main fault would then pass east of the Shetlands.

M. H. Р. ВотT

A. B. WatTs

Department of Geology,

South Road,

Durham.

Received April 15, 1970.

${ }^{1}$ Flinn, D., Geol. J., 6, 279 (1969).

"Aeromagnetic Map of Part of Great Britain, Sheets 15, 16 (Institute of Geological Sciences, 1968).

${ }^{8}$ Vacquier, V., Steeniand, N. C., Henderson, R. G., and Zietz, I., Mem. Geol. Soc. A mer., 47 (1951).

- Bott, M. H. P., and Watts, A. B., Nature, 225, 265 (1970).

- Allen, C. R., Phil. Trans. Roy. Soc., A, 258, 82 (1965).

- McKenzie, D. P., and Parker, R. L., Nature, 216, 1276 (1968).

7 Benioff, H., in Continental Drift (edit. by Runcorn, S. K.), 103 (1962).

- Wellman, H. W., NZ Geol. Surv. Bull., 48 (1955).

- Collette, B. J., in Gravity Expeditions, 1948-58, 5, Part 2, Delft (1960).

${ }^{10}$ Collette, B. J., in Geology of the East Atlantic Continental Margin, SCOR Symposium, Cambridge (1970).

${ }^{21}$ Pitcher, W. S., in North Atlantic-Geology and Continental Drift (edit. by Kay, M.), 724 (1969).

\section{Structure Determination by the Combination of Anomalous Scattering and Direct Methods}

PHASE determination by direct methods is more difficult for non-centrosymmetric than for centrosymmetric erystals. The phase, $\alpha(h, k, l)$, can take any value for the former crystal between 0 and $2 \pi$ while the choice for the latter crystal is limited to two values, 0 or $\pi$ If the structure is non-centrosymmetric and contains a small number of atoms which scatter anomalously, then $\alpha(\mathrm{h}, \mathrm{k}, \mathrm{l})$ can bo determined from the Bijvoet difference, for example, $\Delta I=|F(\mathrm{~h}, \mathrm{k}, \mathrm{l})|^{2}-|F(\overline{\mathrm{h}}, \overline{\mathrm{k}}, \overline{\mathrm{l}})|^{2}$, and the known phase $\alpha_{P}^{\prime}$ of the anomalous scatterers ${ }^{1,2}$. From

and

$$
\alpha_{N}^{\prime}=\alpha_{p}^{\prime}+\pi / 2 \pm \theta
$$

$$
\cos \theta=\frac{\Delta I}{4\left|F_{N}^{\prime}\right|\left|F_{P}^{*}\right|}
$$

where $\alpha_{N}^{\prime}$ is $\alpha(\mathrm{h}, \mathrm{k}, \mathrm{l})$, the phase of the reflexion, $F_{N}^{\prime}$, if there were no anomalous scattering. $F_{P}^{\prime \prime}$ is the contribution from the absorption term $\Delta f_{p}^{\prime \prime}$. The indeterminacy in equation (1) arises because the cosine is an even function. In practice, the ambiguity has been resolved by choosing $\alpha_{N}^{r}$ to be the phase closest to $\alpha_{P}^{\prime}$ (ref. 3) or by calculating a double phased synthesis ${ }^{2}$. An alternative, indeed the original method, is to calculate the Patterson sine function 4 .

A different approach ${ }^{5}$ is to recognize that the incorporation of anomalous scattering data reduces the problem to the comparative simplicity of the centrosymmetric case, or to a choice between two phases, and then to use direct methods to select the observed phase closest to the correct value. An important difference is that the two possible phases $\alpha_{1}$ and $\alpha_{2}$ need no longer be $\pi$ apart.

When $|\cos \theta|_{\text {obs }} \geq 1$ then $\alpha_{1}=\alpha_{2}$ and the phase is known unambiguously. Such reflexions form a basic set from which the phase determination may proceed. For $\mathrm{x}(+)$ lysine hydrochloride dihydrate, using Raman's ${ }^{3}$ data, fifty-two out of 128 phases can be determined unambiguously in this way. Similarly, from the neutron diffraction data for cadmium nitrate tetradeuterate ${ }^{6}$, thirty-two out of 161 phases can be determined.

From the basic set, there are two possible wars of proceeding. Phases for the remaining reflexions can bo calculated and the observed phase closest to the calculated phase can be chosen or, alternatively, phases can be determined and refined without paying further attention to the observed phases. A reasonable approach would be to carry out sufficient cycles of the first alternative to determine as many phases as required, and then to refine them by the second method, because the observed phases will be liable to error. A preliminary cycle in which the basic set alone is refined should be performed because $\alpha_{1}$ for the set may have only a small number of discrete values depending on the space group and the number of anomalous scatterers in the asymmetric unit. For example, for lysine hydrochloride, the phases of the basic set were $90^{\circ}$ or $270^{\circ}$. It should be noted that no arbitrary origin-defining phases can be used because the origin is already determined when placing the anomalous scatterers.

The method described here could be useful for determining the structures of large molecules of biological interest which are often solved by combining multiple isomorphous replacement with anomolous scattering data. An obrious advantage would be in the reduction of the numbr 1 of data to be collected.

\section{A. C. Hazell}

Institute of Chemistry,

Aarhus University,

DK 800 Aarhus C,

Denmark.

Received March 16, 1970.

${ }^{1}$ Peerdeman, A. F., and Bijvoet, J. M., Acta Cryst., 9, 1012 (1956).

2 Ramachandran, G. N., and Raman, S., Curr. Sci., 25, 348 (1956).

${ }^{3}$ Raman, S., Z. Kristallogr., 111, 301 (1959).

4 Okaya, Y., Saito, Y., and Pepinsky, R., Phys. Rev., 98, 1857 (1955)

${ }^{5}$ Hazell, A. C., Seventh Nordiska Strukturkemistmötet, 90 (1970).

- MacDonald, A. C., and Sikka, S. K., Acta Cryst., B, 25, 1804 (1968,.

\section{Supralinearity of Thermoluminescent Phosphor Lithium Fluoride}

THE non-linear response to dose reported for many thermoluminescent phosphors ${ }^{1,2}$ has caused serious concern both for dosimetry and for dating techniques.

We have investigated square samples of TLD-100 phosphor $3 \mathrm{~mm}$ across and $1 \mathrm{~mm}$ thick. The thermoluminescence output induced by a ${ }^{90} \mathrm{Sr}$ source was meastured conventionally with a photomultiplier tube in oxygenfree nitrogen and a heating rate of $20^{\circ} \mathrm{C} / \mathrm{s}$. A dose of a few kilorads was given to the phosphor and the TL output was measured. In addition to the peaks reported by Zimmerman et al.3, a tail was observed at the higher temperature region. A detailed study on this tail showed that there are at least two peaks in its fine structure. These two peaks were found to increase with dose to saturation at near 3 megarads. The peak positions are at $370^{\circ} \mathrm{C}$ and $430^{\circ} \mathrm{C}$ respectively. The structure of this tail and its dependence on dose can be seen from Figs. 1 and 2.

A thermal annealing experiment, was performal in order to study the characteristics of these peaks. Both peaks were found to tail off exponentially at constant 